\title{
First French Experience of ADR Reporting by Patients After a Mass Immunization Campaign with Influenza A (H1N1) Pandemic Vaccines
}

\section{A Comparison of Reports Submitted by Patients and Healthcare Professionals}

\author{
Geneviève Durrieu, ${ }^{1,2}$ Aurore Palmaro, ${ }^{1,2,3}$ Laure Pourcel, ${ }^{1,2}$ Céline Caillet, ${ }^{1,2}$ \\ Angeline Faucher, ${ }^{1,2}$ Alexis Jacquet, ${ }^{4}$ Shéhérazade Ouaret, ${ }^{4}$ Marie Christine Perault-Pochat, ${ }^{5}$ \\ Carmen Kreft-Jais, ${ }^{4}$ Anne Castot, ${ }^{4}$ Maryse Lapeyre-Mestre ${ }^{1,2,3}$ and Jean-Louis Montastruc, ${ }^{1,2}$ \\ on behalf of the French Network of Pharmacovigilance Centres ${ }^{1}$ \\ 1 CHU Toulouse, Service de Pharmacologie Clinique, Pôle Santé-Société, Réadaptation, Faculté de \\ médecine, Toulouse, France \\ 2 Université de Toulouse III, UMR1027, Toulouse, France \\ 3 Inserm, UMR1027, Toulouse, France \\ 4 Agence Française de Sécurité Sanitaire des Produits de Santé (AFSSaPS), Paris, France \\ 5 Association Française des Centres Régionaux de PharmacoVigilance, Paris, France
}

\section{Abstract}

\begin{abstract}
Background: Available data concerning the contribution of patient adverse drug reaction (ADR) reporting in practice are scarce. Few studies have compared patients' reports with reports from healthcare professionals (HCPs). During the 2009-10 mass immunization campaign with A (H1N1)v2009 pandemic influenza vaccines, a reinforced pharmacovigilance plan was introduced in France according to European Medicines Agency recommendations. For the first time, patients were offered the opportunity to report suspected ADRs to pandemic vaccines directly to regional pharmacovigilance centres.

Objective: The aim of the study was to compare the characteristics of patient and HCP ADR reports in order to assess the qualitative and quantitative contribution of patient reporting to the French Pharmacovigilance System.
\end{abstract}

1 French Network of Pharmacovigilance Centres (CRPV): E. Autret-Leca, Tours; B. Baldin, Nice; F. Bavoux, Paris St-Vincent de Paul; A. Bénard-Laribière, Bordeaux; M. Biour, Paris St-Antoine; M.N. Beyens, SaintEtienne; F. Colin, Rennes; A. Cocquerel, Caen; S. Crepin, Limoges; G. Décréau-Gaillon, Rouen; S. Dos Santos, Paris Henri Mondor; P. Eftekhari, Paris Fernand-Widal; S. Favrelière, Poitiers; M.C. Perault-Pochat, Poitiers; S. Gautier, Lille; V. Gras-Champel, Amiens; L. Javot, Nancy; M.J. Jean-Pastor, Marseille; C. Le Beller, Paris HEGP; B. Lebrun-Vignes, Paris Pitié-Salpétrière; A. Millaret, Lyon; A. Perrazi, Clermont-Ferrand; V. Pinzani, Montpellier; C. Riché, Brest; E. Schir, Grenoble; C. Sgro, Dijon; M. Tebacher-Alt, Strasbourg; T. Trenque, Reims; M.B. Valnet-Rabier, Besançon; G. Veyrac, Nantes. 
Methods: All spontaneous ADRs registered into the French Pharmacovigilance Database from 21 October 2009 to 15 June 2010, in which either one of the most frequently administered pandemic vaccines (i.e. Panenza ${ }^{\circledR}$ or Pandemrix ${ }^{\circledR}$ ) was involved, were analysed. ADRs were classified as 'serious', 'medically serious' and 'non-serious'. This study focused on 'serious' and 'medically serious' ADRs. An ADR was ranked as 'medically serious' when it required medical intervention or hospitalization within less than 24 hours. In each level of seriousness, frequency of 'unlabelled' ADRs, ADRs of 'special interest', imputability scores and category of ADRs according to Medical Dictionary for Regulatory Activitives (MedDRA ${ }^{\circledR}$ ) primary System Organ Class were compared between patient and professional reports.

Results: Among the 4746 reports received during the study period, 1006 (21.2\%) originated from patients. HCPs reported significantly more 'medically serious' or 'serious' ADRs than patients (15.1\% [565/3740] vs 8.4\% [85/1006], respectively; $\mathrm{p}<0.001)$. No difference was found in 'unlabelled, serious' ADRs between patients and HCPs $(56.5 \%[n=13]$ vs $56.7 \%[n=136]$, respectively).

Conclusions: In this first French experience of formal patient participation to ADR reporting, patient contribution to the total number of ADRs reached $21.2 \%$. This study revealed no major qualitative difference between patient and HCP reports. ADR profiles reported by patients appeared to be consistent with those from professionals. Further investigations are necessary to assess the intrinsic quality of notification forms coming from non-professional reporters. However, this study is of particular interest in the context of publication of the first governmental decree that will formally integrate patient participation to the current French ADR reporting scheme.

\section{Background}

During the 2009-10 mass immunization campaign in France, 5.7 million doses of A (H1N1)v2009 pandemic vaccines were administered, according to French national authorities (1.6 million doses for Panenza ${ }^{\circledR}$ and 4.1 million doses for Pandemrix $\left.{ }^{\circledR}\right) .{ }^{[1]}$ Panenza ${ }^{\circledR}$ was mainly recommended for prophylaxis of influenza in an officially declared pandemic situation for pregnant women and children under the age of 9 years, whereas Pandemrix ${ }^{\circledR}$ was administered in adults and children over 9 years of age. ${ }^{[2-4]}$

In the context of pandemic influenza, A (H1N1)v2009 vaccines were approved by the European Medicines Agency (EMA) after an accelerated assessment procedure. To enhance safety data collection, which would facilitate detection of a potential safety signal, a reinforced monitor- ing plan was introduced in France, according to the recommendations of the EMA. ${ }^{[5]}$ For these purposes, patients were also involved in the data collection process. For the first time in France, patients or relatives could report an adverse drug reaction (ADR) following influenza A (H1N1)v2009 vaccine administration directly to Regional Pharmacovigilance Centres (RPVCs). They were informed of this possibility through a media campaign (newspapers and television). Information was also dispensed in mass vaccination centres, in which notification forms were made available. Patient notification forms could also be downloaded from the French Medicines Agency (Afssaps) website. ${ }^{[6]}$ Patients had to complete the notification form and send it by post or email to the appropriate RPVC that covers their area of residence. Healthcare professionals (HCPs) were able to submit ADR reports by post, email or 
online through the French Medicines Agency website. ${ }^{[7]}$ In case of exclusive online submission, HCPs were required to fill in mandatory fields related to seriousness of the ADR, the type of $\mathrm{HCP}$ and the postal code of the reporter in order to redirect the ADR report to the corresponding RPVC.

A recent study by Avery et al. ${ }^{[8]}$ has listed 46 countries with a patient reporting scheme. However, little evidence is available concerning the quality and extent of patient reporting in current practice. Our objective was to compare the characteristics of patient and HCP ADR reports collected during the influenza A (H1N1)v2009 immunization campaign in order to assess the qualitative and quantitative contribution of patient reporting to the French Pharmacovigilance Database.

\section{Methods}

\section{Data Collection and Settings}

All spontaneous ADRs registered into the French Pharmacovigilance Database (FPVD) from 21 October 2009 to 15 June 2010, in which either one of the most administered pandemic vaccines (i.e. Panenza ${ }^{\circledR}$ or Pandemrix ${ }^{\circledR}$ ) was involved, were analysed. ADRs in pregnant women are not included in this study but are described elsewhere. ${ }^{[9]}$

\section{Management of Patient Notification Forms}

The French pharmacovigilance system consists of a network of 31 regional centres (RPVC) and is based on a spontaneous surveillance system in which reports of 'serious' and/or 'unlabelled' adverse events (AEs) are mandatory for all $\mathrm{HCPs}{ }^{[10]}$ Notification forms from patients were treated and processed in the same way as forms from HCPs. Medical confirmation of patient declarations was not mandatory. However, patients were encouraged to seek assistance from a medical practitioner to complete the form, and to attach any relevant medical reports confirming diagnosis, treatments or outcome concerning the reaction reported.

Imputability was scored according to the French ADR causality assessment method, defined by Begaud et al. ${ }^{[11]}$ This method is based on a combination of two scores (chronological and semi- ological imputability). All suspected ADRs were classified by each RPVC into four categories, according to causality levels (i.e. I1: 'possible'; I2: 'plausible'; I3: 'likely'; I4: 'very likely').

The RPVC of Toulouse (Midi-Pyrénées area, South-Western France) was charged by the French Medicines Agency to coordinate the management of ADR reports occurring during this influenza A (H1N1)v2009 mass influenza immunization campaign. Each report was reviewed and analysed by an expert committee, established only for the purpose of the reinforced pharmacovigilance plan, and consisting of the coordinator of the pharmacovigilance centre (RPVC of Toulouse), representatives of the French Network of Pharmacovigilance Centres, the French Medicines Agency and Marketing Authorization Holders (MAH).

\section{Duplicated Reports}

To avoid duplicate reports, sent from both patients and their healthcare providers, a request for previously entered reports was made at regional level within the FPVD, using patient sex and birthdate as matching criteria.

\section{Classification of Reporters}

In the FPVD, the persons submitting suspected ADR forms (hereinafter called 'reporters') are classified into eight categories. HCPs are classified into six categories, including general practitioners, specialist doctors, pharmacists, dentists, nurses and other HCPs. The 'patient' category included not only patients who had experienced an ADR and submitted a notification form, but also their relatives who had also reported ADRs. Lawyers are also included in the 'patient' category. For the purpose of the study, we categorized reporters into 'HCPs' and 'patients'. Notification forms coming from the MAH were also classified according to these two categories.

\section{Pandemic Influenza A (H1N1)v2009 Vaccines}

ADRs involving one of the most administered pandemic vaccines, i.e. either Panenza ${ }^{\circledR}$ [non-adjuvanted inactivated split virion vaccine containing A/California/7/2009 v-like strain (NYMC X-179A), 
Sanofi Pasteur, Inc.] or Pandemrix ${ }^{\circledR}[\mathrm{H} 1 \mathrm{~N} 1 \mathrm{AS} 03-$ adjuvanted inactivated split virion vaccine containing $\mathrm{A} /$ California/7/2009 (H1N1) v-like strain (X. 179A), GlaxoSmithKline, Inc.], were included.

\section{Definitions and Classification of Adverse Drug Reactions (ADRs)}

A 'serious' ADR is "any untoward medical occurrence that at any dose results in death, requires hospital admission or prolongation of existing hospital stay, results in persistent or significant disability/incapacity, or is life threatening". ${ }^{[12]}$ An ADR is classified as being 'medically serious' when it requires medical intervention, or hospitalization within less than 24 hours of onset to prevent one of the outcomes listed in the serious ADR definition. An 'unlabelled' ADR is a reaction whose nature or severity is not consistent with data contained in domestic labelling or market authorization, or expected from the characteristics of the drug. ${ }^{[12]}$ Moreover, the EMA have defined some ADRs of 'special interest'. ${ }^{[5]}$ For pandemic vaccines, the following ADRs were considered: neuritis, convulsions, anaphylaxis, encephalitis, vasculitis, Guillain-Barré syndrome, Bell's palsy, demyelinating disorders and laboratory-confirmed immunization failure.

\section{Data Analysis}

ADRs were classified as 'serious', 'medically serious' or 'non-serious'. In this study, we considered only the reports ranked either 'serious' or 'medically serious'. At these two levels of 'seriousness', the frequency of 'unlabelled' ADRs, ADRs of 'special interest', imputability scores and category of ADRs according to the Medical Dictionary for Regulatory Activities (MedDRA $\left.{ }^{\circledR}\right)$ primary System Organ Class (SOC) were compared between patient and professional reports. MedDRA ${ }^{\circledR}$ terminology is the international medical terminology developed under the auspices of the International Conference on Harmonization of Technical Requirements for Registration of Pharmaceuticals for Human Use (ICH). Comparisons between categories of reporters were made using the Chi-squared test. As differences in safety profiles between pandemic vaccines could be suspected, statistical analyses were adjusted for suspected products. Statistical analyses were performed using SAS ${ }^{\circledR}$ Software v.9.2 (SAS Institute Inc., Cary, NC, USA) with a two-sided $\alpha$-level of 0.05 .

\section{Results}

Distribution of ADRs According to Seriousness

Among the 4746 reports received during the study period, $1006(21.2 \%)$ originated from patients and $3740(78.8 \%)$ from HCPs. Table I shows the distribution of 'seriousness' according to reporter category. Patients and HCPs reported more 'nonserious' ADRs than 'medically serious' or 'serious' ADRs. However, HCPs reported significantly more 'serious' or 'medically serious' ADRs than patients $(15.1 \%$ [565/3,740] vs $8.4 \%$ [85/1,006], respectively; $\mathrm{p}<0.001)$. Table II presents reporter characteristics in both levels of 'seriousness'.

\section{Description of Causality Assessment Scores and Unlabelled ADR Frequencies}

Table III shows the detail of causality scores assigned to 'unlabelled, serious' and 'unlabelled, medically serious' ADRs, according to reporter category. Overall, 91.3\% (21/23) of the 'serious' ADRs reported by patients were ranked I1 ('possible') and $8.7 \%(2 / 23)$ were ranked I2 ('plausible') vs $84.6 \%(203 / 240)$ and $10.0 \%(24 / 240)$, respectively, for HCP reports. The score I3 ('likely') was attributed to only 13 ADRs reported by HCPs $(5.4 \%[13 / 240])$ and to none from patients. Concerning 'unlabelled' ADRs, patients reported $13(56.5 \%)$ 'unlabelled, serious' ADRs, including $12(52.2 \%)$ ranked I1 ('possible') and 1 (4.3\%) ranked I2 ('plausible'). HCPs reported 136 'unlabelled, serious' ADRs, including 127 (52.9\%) ranked I1 ('possible'), 8 (3.3\%) were ranked I2 ('plausible') and $1(0.5 \%)$ ranked I3 ('likely').

Moreover, patients reported 16 (25.8\%) 'unlabelled, medically serious' ADRs: 14 (22.6\%) ranked I1 ('possible') and $2(3.2 \%)$ ranked I2 ('plausible'). Among the 103 'unlabelled, medically serious' ADRs reported by HCPs, 91 (28.0\%) were classified I1 ('possible') and 12 (3.7\%) were classified I2 ('plausible'). 
Table I. Distribution of 'seriousness' levels according to reporter category

\begin{tabular}{|c|c|c|c|c|}
\hline & $\begin{array}{l}\text { Total } \\
(n=4746)[n(\%)]\end{array}$ & $\begin{array}{l}\text { Patients } \\
(n=1006)[n(\%)]\end{array}$ & $\begin{array}{l}\text { HCP } \\
(n=3740)[n(\%)]\end{array}$ & $p-$ Value $^{a}$ \\
\hline 'Serious' ADRs' & $263(5.5)$ & $23(2.3)$ & $240(6.4)$ & NS \\
\hline 'Non-serious' ADRs & 4096 (86.3) & 921 (91.5) & 3175 (84.9) & NS \\
\hline
\end{tabular}

a Chi-squared test.

b A 'serious' ADR is "any untoward medical occurrence that at any dose results in death, requires hospital admission or prolongation of existing hospital stay, results in persistent or significant disability/incapacity, or is life threatening".

C A reaction is ranked 'medically serious' when it requires medical intervention, or hospitalization within less than 24 hours of onset to prevent one of the outcomes listed in the serious ADR definition.

ADRs = adverse drug reactions; $\mathbf{H C P s}=$ healthcare professionals; $\mathbf{N S}=$ not significant.

No difference was found in 'unlabelled, serious' ADRs between patients and HCPs (56.5\% [n $=13]$ vs $56.7 \%[\mathrm{n}=136]$, respectively). Similarly, the frequency of 'unlabelled, medically serious' ADRs in the patient category was not statistically significantly different from that of the HCP group.

\section{Characteristics of Reported ADRs}

Tables IV and V show the distribution of 'serious' and 'medically serious' ADRs by decreasing order of frequency of the primary SOC. 'Nervous system disorders', 'General disorders and administration site conditions' and 'Respiratory, thoracic and mediastinal disorders' were the most frequently reported SOCs in both reporter categories for 'serious' ADRs. 'General disorders and administration site conditions', 'Nervous system disorders' and 'Musculoskeletal and connective tissue disorders' were the most frequently reported SOCs for the 'medically serious' ADRs. Among the 73 reported cases of ADRs of 'special interest', 3 (4.1\%) were reported by patients: two convulsion episodes (in a 10-month-old baby and in an adult aged 28 years) and one case of vasculitis in a 5-year-old child.

\section{Discussion}

First Safety Data on Pandemic Vaccines from Patients in a Context of Mass Immunization Campaign Against Influenza A (H1N1)v2009

This study relates to the first experience of formal integration of patients reporting in a reallife, large-scale, safety monitoring system in France.
Before the 2009-10 mass immunization campaign, direct reporting by patients was not allowed in France, although a former French pilot study has already assessed the feasibility of patient participation. ${ }^{[13]}$ In this pilot experiment, patient organizations were involved to assist patients in completing the reporting form and in the data collection process. This study revealed that patient reporting, with the assistance of organizations, could be contributive. However, such a measure was not implemented during the 2009-10 mass immunization campaign.

Table II. Categories of reporters for 'serious' and 'medically serious' adverse drug reactions

\begin{tabular}{lcc}
\hline Type of reporter & $\begin{array}{c}\text { 'Serious' ADRs } \\
(\mathrm{n}=263)[\mathrm{n}(\%)]\end{array}$ & $\begin{array}{l}\text { 'Medically serious' } \\
\mathrm{ADRs}^{\mathrm{b}} \\
(\mathrm{n}=387)[\mathrm{n}(\%)]\end{array}$ \\
\hline Healthcare professionals & $\mathbf{2 4 0 ( 9 1 . 3 )}$ & $\mathbf{3 2 5 ( 8 4 . 0 )}$ \\
Specialist doctors & $173(65.8)$ & $188(48.6)$ \\
General practitioners & $38(14.4)$ & $98(25.3)$ \\
Pharmacists & $19(7.2)$ & $13(3.4)$ \\
Other health professionals & $6(2.3)$ & $10(2.6)$ \\
Dentists & $2(0.8)$ & $5(1.3)$ \\
Nurses & $2(0.8)$ & $11(2.8)$ \\
Patients and relatives & $23(8.7)$ & $\mathbf{6 2 ( 1 6 . 0 )}$ \\
Patients and relatives & $22(8.3)$ & $62(16.0)$ \\
Jurist & $1(0.4)$ & $0(0.0)$ \\
\hline
\end{tabular}

a A 'serious' ADR is "any untoward medical occurrence that at any dose results in death, requires hospital admission or prolongation of existing hospital stay, results in persistent or significant disability/incapacity, or is life threatening".

b A reaction is ranked 'medically serious' when it requires medical intervention, or hospitalization within less than 24 hours of onset to prevent one of the outcomes listed in the serious ADR definition.

ADRs $=$ adverse drug reactions 
Table III. Distribution of causality assessment scores ${ }^{\mathrm{a}}$ for 'unlabelled, ${ }^{\mathrm{b}}$ serious ${ }^{\text {'c }}$ and 'unlabelled, medically serious ${ }^{\text {,d }}$ adverse drug reactions according to reporter category

\begin{tabular}{|c|c|c|c|c|c|c|c|c|}
\hline \multirow[t]{3}{*}{ Causality score $\mathrm{a}^{\mathrm{a}, \mathrm{e}}$} & \multicolumn{4}{|c|}{ 'Serious' ADRs $(n=263)[n(\%)]$} & \multicolumn{4}{|c|}{ 'Medically serious' ADRs $(n=387)[n(\%)]$} \\
\hline & \multicolumn{2}{|c|}{ Patients $(n=23)$} & \multicolumn{2}{|c|}{ HCPs $(n=240)$} & \multicolumn{2}{|c|}{ Patients $(n=62)$} & \multicolumn{2}{|c|}{ HCPs $(n=325)$} \\
\hline & Unlabelled & $\overline{\text { Labelled }}$ & Unlabelled $^{f}$ & Labelled & Unlabelled & Labelled & Unlabelled $^{f}$ & Labelled \\
\hline 11: 'possible' & $12(52.2)$ & $9(39.1)$ & $127(52.9)$ & $76(31.7)$ & $14(22.6)$ & $33(53.2)$ & $91(28.0)$ & $133(40.9)$ \\
\hline I2: 'plausible' & $1(4.3)$ & $1(4.3)$ & $8(3.3)$ & $16(6.7)$ & $2(3.2)$ & $10(16.1)$ & $12(3.7)$ & $68(20.9)$ \\
\hline I3: 'likely’ & $0(0.0)$ & $0(0.0)$ & $1(0.5)$ & $12(5.0)$ & $0(0.0)$ & $3(4.8)$ & $0(0.0)$ & $21(6.5)$ \\
\hline Total & $13(56.5)$ & $10(43.5)$ & $136(56.7)$ & 104 (43.3) & $16(25.8)$ & 46 (74.2) & $103(31.7)$ & $222(68.3)$ \\
\hline
\end{tabular}

a According to the French ADR causality assessment method. ${ }^{[11]}$ All suspected ADRs are classified into one of four causality levels: I1: 'possible'; I2: 'plausible'; I3: 'likely'; I4: 'very likely'.

b An 'unlabelled' ADR is a reaction whose nature or severity is not consistent with data contained in domestic labelling or market authorization, or expected from characteristics of the drug.

c A 'serious' ADR is "any untoward medical occurrence that at any dose results in death, requires hospital admission or prolongation of existing hospital stay, results in persistent or significant disability/incapacity, or is life threatening".

d A reaction is ranked 'medically serious' when it requires medical intervention, or hospitalization within less than 24 hours of onset to prevent one of the outcomes listed in the 'serious' ADR definition.

e No observation was ranked 14 ('very likely').

f Chi-squared comparison of the frequencies of unlabelled ADRs between patients and HCPs for 'serious' and 'medically serious' ADRs were not significant.

ADRs $=$ adverse drug reactions; $\mathbf{H C P s}=$ healthcare professionals.

\section{Quantitative Contribution of Patient Reports}

From 28 October 2009 to 15 June 2010, 4746 notification forms extracted from the FPVD were analysed. Among the 4746 forms received, 1006
(21.2\%) originated from patients and $3740(78.8 \%)$ originated from HCPs.

Patient contribution to the total number of ADRs reported was comparable to that observed in other existing patient reporting schemes. For

Table IV. Top ten of the most frequently reported 'serious' adverse drug reactions, by primary System Organ Class

\begin{tabular}{|c|c|c|c|}
\hline$\overline{\mathrm{SOC}}$ & $\begin{array}{l}\text { Patients } \\
(n=22)[n(\%)]\end{array}$ & $\begin{array}{l}\mathrm{HCPs} \\
(\mathrm{n}=227)[\mathrm{n}(\%)]\end{array}$ & $\begin{array}{l}\text { Total } \\
(\mathrm{n}=249)[\mathrm{n}(\%)\end{array}$ \\
\hline Nervous system disorders $^{a}$ & $6(29.1)$ & $95(39.6)$ & $101(38.4)$ \\
\hline General disorders and administration site conditions ${ }^{b}$ & $5(21.7)$ & $47(19.6)$ & $52(19.8)$ \\
\hline Respiratory, thoracic and mediastinal disorders ${ }^{c}$ & $4(17.4)$ & $20(8.3)$ & $24(9.1)$ \\
\hline Blood and lymphatic system disorders ${ }^{d}$ & $1(4.4)$ & $17(7.1)$ & $18(6.8)$ \\
\hline Immune system disorders ${ }^{\mathrm{e}}$ & $0(0.0)$ & $12(5.0)$ & $12(4.6)$ \\
\hline Musculoskeletal and connective tissue disorders & $0(0.0)$ & $11(4.6)$ & $11(4.2)$ \\
\hline Vascular disorders & $2(8.7)$ & $8(3.3)$ & $10(3.8)$ \\
\hline Skin and subcutaneous tissue disorders & $0(0.0)$ & $9(3.8)$ & $9(3.4)$ \\
\hline Gastrointestinal disorders & $3(13.0)$ & $4(1.7)$ & $7(2.7)$ \\
\hline Cardiac disorders & $1(4.4)$ & $4(1.7)$ & $5(1.9)$ \\
\hline \multicolumn{4}{|c|}{$\begin{array}{l}\text { Mainly includes paraesthesia, Guillain-Barré syndrome, demyelinating disorders and febrile convulsions (Guillain-Barré syndrome anc } \\
\text { demyelinating disorders were exclusively reported by HCPs). }\end{array}$} \\
\hline \multicolumn{4}{|c|}{ b Includes, for instance, influenza-like illness, malaise or fever. } \\
\hline \multicolumn{4}{|l|}{ c Mainly includes bronchopneumopathy. } \\
\hline \multicolumn{4}{|l|}{ d Mainly includes thrombocytopenic purpura. } \\
\hline \multicolumn{4}{|l|}{ e Mainly includes anaphylactic shock and angioedema. } \\
\hline \multicolumn{4}{|c|}{ HCPs $=$ healthcare professionals; $\mathbf{S O C}=$ System Organ Class.} \\
\hline
\end{tabular}


Table V. Top ten of most frequently reported 'medically serious' adverse drug reactions, by primary System Organ Class

\begin{tabular}{|c|c|c|c|}
\hline$\overline{\mathrm{SOC}}$ & $\begin{array}{l}\text { Patients } \\
(n=62)[n(\%)]\end{array}$ & $\begin{array}{l}\text { HCPs } \\
(n=312)[n(\%)]\end{array}$ & $\begin{array}{l}\text { Total } \\
(n=374)[n(\%)\end{array}$ \\
\hline General disorders and administration site conditions $^{a}$ & $17(27.4)$ & $114(35.1)$ & $131(33.9)$ \\
\hline Nervous system disorders ${ }^{\mathrm{b}}$ & $17(27.4)$ & $85(26.2)$ & $102(26.6)$ \\
\hline Musculoskeletal and connective tissue disorders ${ }^{c}$ & $14(22.6)$ & $31(9.5)$ & $45(11.6)$ \\
\hline Skin and subcutaneous tissue disorders ${ }^{d}$ & $9(14.5)$ & $31(9.5)$ & $40(10.3)$ \\
\hline Immune system disorders ${ }^{e}$ & $1(1.6)$ & $15(4.6)$ & $16(4.1)$ \\
\hline Respiratory, thoracic and mediastinal disorders & $0(0.0)$ & $12(3.7)$ & $12(3.1)$ \\
\hline Vascular disorders & $2(3.2)$ & $7(2.2)$ & $9(2.3)$ \\
\hline Gastrointestinal disorders & $0(0.0)$ & $6(1.9)$ & $6(1.6)$ \\
\hline Cardiac disorders & $1(1.6)$ & $4(1.2)$ & $5(1.3)$ \\
\hline Blood and lymphatic system disorders & $1(1.6)$ & $4(1.2)$ & $5(1.3)$ \\
\hline Hepatobiliary disorders & $0(0.0)$ & $3(0.9)$ & $3(0.8)$ \\
\hline \multicolumn{4}{|c|}{ a Includes, for instance, influenza-like illness, local reactions or fever. } \\
\hline \multicolumn{4}{|c|}{ b Includes, for instance, paraesthesia, dizziness, headache or febrile convulsion. } \\
\hline \multicolumn{4}{|l|}{ c Includes, for instance, myalgia or arthralgia. } \\
\hline \multicolumn{4}{|l|}{ d Includes cutaneous reaction and urticarial. } \\
\hline \multicolumn{4}{|l|}{ e Mainly includes angioedema. } \\
\hline HCPs $=$ healthcare professionals; $\mathbf{S O C}=$ System Orga & & & \\
\hline
\end{tabular}

instance, in Denmark, patient contribution to the total number of ADR reports was $19 \%$ in 2008..$^{[14]}$ In the US, patients can voluntarily report AEs through the MedWatch programme. These reports represented $15 \%$ of the total reports received in 2004, but most of them originated from the MAH. ${ }^{[15]}$ However, a recent Dutch publication on AE monitoring during the influenza A (H1N1)v2009 immunization campaign reported higher consumer participation than previously described in other studies. ${ }^{[16]}$ In this study, consumers sent $2226(79.8 \%)$ of the reports on Focetria ${ }^{\circledR}$ and $3889(81.9 \%)$ of the reports on Pandemrix ${ }^{\circledR}$ to the Netherlands Pharmacovigilance Centre (Lareb). Extensive media coverage concerning potential safety issues of pandemic vaccines could have introduced a bias in the magnitude of ADR reporting, not only from patients but also from HCPs, as observed in other countries. ${ }^{[16]}$ Estimating the precise magnitude of this popularization bias and how it affected the levels of notification efficiency remains difficult. However, in order to assess notification efficiency, we can compare the reporting rate observed during previous French experiences and for other existing patient reporting schemes at international level. During the 2009-10 influ- enza A (H1N1)v2009 mass immunization campaign, 46.2 'serious' ADRs per 1000000 doses administered were recorded in the FPVD (263 per 5.7 million doses administered). ${ }^{[17]}$ In a passive monitoring system such as the Vaccine Adverse Event Reporting System, during the 1990-2005 time period, the reporting rate for 'serious' ADRs was 3.4 per 1000000 vaccine doses. ${ }^{[18]}$ In a previous French experience with an extensive pharmacovigilance follow-up (meningococcal serogroup C immunization campaign, October 2002), reporting rate reached 1350 per 1000000 doses administered. ${ }^{[19]}$

\section{Qualitative Contribution of Patients' Reports}

HCPs and patients reported more 'non-serious' than 'medically serious' or 'serious' ADRs. However, HCPs reported significantly more 'serious' or 'medically serious' ADRs than patients. These results could be linked to the clinical management of ADRs ranked as 'serious' or 'medically serious'. By definition, these ADRs are more likely to require the patient to have a medical consultation than 'non-serious' ADRs; therefore, HCPs might tend to report ADRs with higher level of seriousness. 
The frequency of ADRs ranked 'serious' has already been used as an indirect indicator of the contribution of patient reports. This criterion must nevertheless be used with caution, as suggested by Blenkinsopp et al. ${ }^{[20]}$

Among 'serious' ADRs, the percentage of 'unlabelled' ADRs was relatively high (more than $50 \%$ of the total ADRs) and was not statistically different between reporter categories. To justify the integration of patients into an ADR monitoring system, it is often argued that patients could enable the earlier identification of 'unlabelled' ADRs. ${ }^{[14,21,22]}$ This phenomenon was not observed during our study and this result could be linked to the recent introduction of both pandemic vaccines on the market and to the particular context of a mass immunization campaign (role of mass media).

Adverse effect profiles at SOC level appeared to be quite similar according to reporter category. In one way, patient reports did not reveal any qualitative differences. In another way, this consistency with professional reporters could be considered as a criterion of reliability and credibility. The quantitative contribution of patient reports, which would result in an overall increase in the number of ADR reports, could be sufficient by itself to justify the interest of patient participation. However, this assumption is contingent on the hypothesis that the quality and consistency of patients' ADR reports could be ascertained. Moreover, another factor to consider is that patient report management could be a time-consuming and complex process. ${ }^{[14]}$ However, in our experience, the constraints induced by patient reporting were not formally assessed.

\section{Causality Assessment}

Most ADRs were ranked I1 ('possible'), and the percentage did not differ between reporter categories. Only a few of these reports were classified into the category I3 ('likely'). These findings appear to be consistent with results involving other vaccines, and are probably due to the particular characteristics of vaccines compared with other medications, which makes the assessment of a causal relationship with the occurrence of an ADR particularly difficult. ${ }^{[23]}$

\section{Strengths and Limitations}

Studies performed on safety databases could be limited by a potential discordance between the data source and the data analysed. ${ }^{[24]}$ Thus, information input into the FPVD may be considered as a modified version of the original notification forms completed by the reporters. Due to this alteration, the intrinsic quality of initial patient reports cannot be assessed. However, the assessment criteria chosen in this study provide an indirect assessment of the 'quality' of patient reports (qualitative contribution). In addition, the strategy of data collection and treatment used by the RPVCs contributed to increase the level of completeness and informativity of initial patient reporting forms.

Similarly, we have not been able to describe the characteristics nor establish a profile of nonprofessional reporters, since demographic data entered into the FPVD are exclusively linked to the patients who experienced an ADR.

Furthermore, this study focused on a single type of product (e.g. monovalent pandemic vaccine). The resulting safety data are relatively homogeneous. We can make an hypothesis that our findings are also highly dependent on the context of the study. Extensive media coverage of pandemic influenza and the mass immunization campaign, especially concerning the potential concerns of adjuvanted vaccines, could have greatly influenced the rate and profile of the notification forms received. Unfortunately, frequencies of ADRs in the different categories were not sufficient to perform statistical tests adjusted for vaccines.

\section{Background and International Experience}

This first French experience of formal integration of patient reporting in a real-life, largescale, safety monitoring system was implemented in the particular context of a special public health concern (pandemic influenza). This makes analysis and interpretation of our results difficult and direct comparison with findings from international experiences hazardous. Patient reporting has already been integrated in the spontaneous safety reporting system in more than 40 countries. ${ }^{[8,14,20]}$ 
However, little evidence is available about the contribution of patient reporting to the pharmacovigilance system. In particular, few comparative studies (patient vs professional reports) have been retrieved. ${ }^{[25-29]}$

In 2009, a Dutch study by Van Hunsel et al. [27] assessed patient reports following a television programme on the benefits and risks of statins. Some differences were observed in the category of ADRs, according to the primary SOC and Preferred Term, but no difference was observed in the level of seriousness. In England, another comparative study studied patient reports after media attention about possible safety issues of paroxetine. ${ }^{[28]}$ Professional reports submitted to the Yellow Card Scheme were compared with data extracted from emails sent by patients. Patient reports were found to be more detailed than HCP reports. This finding was retrieved in more recent studies on patient reports submitted to the Yellow Card Scheme. ${ }^{[8]}$ From 2004 to 2006, Aagaard et al. ${ }^{[24]}$ made a comparative analysis of ADRs reported to the Danish Pharmacovigilance Database by patients and HCPs. Differences were also found among the most frequently reported primary SOCs, but the classification according to seriousness did not differ according to reporter category. In another large-scale study performed on the Netherlands Pharmacovigilance Centre Lareb database, ${ }^{[30]}$ significant differences were observed in the distribution of reports by primary SOC. In this study, no difference was found in the percentage of 'serious' ADR reports between patients and HCPs.

In these papers, various methodologies of data collection or analysis are encountered (format of patient 'forms', postal questionnaire and telephone interview). ${ }^{[24,25,27-28]}$ In particular, some comparative analysis between patient and HCP reports were based on different data sources and/ or different data collection methodologies. ${ }^{[25,28]}$ In the present study, the integration of patient participation as part of an existing system, with no substantial difference in data collection, treatment or encryption processes, ensures a satisfying comparability between patient and $\mathrm{HCP}$ reports.

\section{Conclusions}

In this first French experience of formal patient participation to ADR reporting, patient contribution to the total number of ADRs reached $21.2 \%$. This study revealed no major qualitative differences between patient and HCP reports. The profile of ADRs reported by patients appeared to be consistent with that of professionals. Further investigations are necessary to assess the intrinsic quality of notification forms coming from non-professional reporters. However, this study is of particular interest in the context of the publication of the first governmental decree that would formally integrate patient participation to the current French ADR reporting scheme. ${ }^{[31]}$

\section{Acknowledgements}

The authors would like to thank the following for their valuable support during the Pharmacovigilance survey of A (H1N1)v2009 pandemic vaccines: P. Auriche, V. Pizzoglio (AFSSAPS), M. Clanet, L. Sailler, C. Paul (experts, CHU de Toulouse, France), F. Despas, A. Pathak, S. Bonenfant, N Laplace, S. Fourcade, M Bouin (Service de Pharmacologie Clinique et Médicale, Faculté de Médecine, Université de Toulouse) and the pharmacovigilance departments of the pharmaceutical laboratories Baxter, GSK, Novartis and Sanofi-Pasteur.

No sources of funding were used to conduct this study or prepare this manuscript. The authors have no conflicts of interest that are directly relevant to the content of this study. The MedDRA ${ }^{\circledR}$ trademark is owned by the International Federation of Pharmaceutical Manufacturers \& Associations (IFPMA) on behalf of the ICH.

\section{References}

1. Bone A, Guthmann J-P, Nicolau J, et al. Population and risk group uptake of $\mathrm{H} 1 \mathrm{~N} 1$ influenza vaccine in mainland France 2009-2010: results of a national vaccination campaign. Vaccine 2010; 28 (51): 8157-61

2. Afssaps. Résumé des caracteristiques du produit. Panenza ${ }^{\circledR}$ [online]. Available from URL: http://ansm.sante.fr/var/ ansm site/storage/original/application/104a750b0148a09fe 260689d76604aaa.pdf [Accessed 2012 Aug 6]

3. European Medicines Agency. Summary of product characteristics: Pandemrix ${ }^{\circledR}$. (EMEA/H/C/000832 -II/0048) [online]. Available from URL: http://www.ema.europa.eu/docs/ fr_FR/document library/EPAR - Product Information/ hüman/000832/WC500038121.pdf [Accessed 2010 Oct 21]

4. Haut Conseil de la santé publique. [Guidance on health priority setting for the use of pandemic vaccines against A(H1N1)v influenza virus]. Avis du HCSP du 7 septembre 2009 relatif aux recommandations sur les priorités sanitaires d'utilisation des vaccins pandémiques dirigés contre le virus 
grippal A(H1N1)v [in French; online]. HCSP, Paris, 2009. Available from URL: http://www.sante.gouv.fr/IMG/pdf/ Avis_recos_priorites_vaccin._Ahln1-07-09-09-2.pdf [Accessed 2012 Aug 6]

5. European Medicines Agency. CHMP recommendations for the pharmacovigilance plan as part of the risk management plan to be submitted with the marketing authorisation application for a pandemic influenza vaccine [online]. Available from URL: http://www.emea.europa.eu/docs/en GB/doc ument_library/Report/2010/01/WC500051739.pdf [Accessed 2010 Oct 21]

6. Afssaps. Vaccins et antiviraux contre le virus grippal A $(\mathrm{H} 1 \mathrm{~N} 1) \mathrm{v}$. Fiche patient de déclaration des événements Indésirables [online]. Available from URL: http://ansm. sante.fr/var/ansm_site/storage/original/application/923e41 2bb8a3227e36372b86775dd303.pdf [Accessed 2012 Aug 31]

7. Afssaps. Vaccins et antiviraux contre le virus grippal A (H1N1)v. Fiche Professionnel de Santé de déclaration des événements indésirables [online]. Available from URL: http://ansm.sante.fr/var/ansm_site/storage/original/appli cation/9a64037cdc90fae0adf4e2b387f90d5d.pdf [Accessed 2012 Aug 31]

8. Avery AJ, Anderson C, Bond CM, et al. Evaluation of patient reporting of adverse drug reactions to the UK 'Yellow Card Scheme': literature review, descriptive and qualitative analyses, and questionnaire surveys. Health Technol Assess May 2011; 15 (20): 1-234, iii-iv

9. Lacroix I, Damase-Michel C, Kreft-Jais C, et al. 2009 H1N influenza vaccines in pregnant women: the French Pharmacovigilance survey. Vaccine Feb 2010; 29(7): 1357-8

10. Moore N, Kreft-Jais C, Dhanani A. Spontaneous reporting: France. In: Mann RD, Andrews E, (editors). Pharmacovigilance, 2nd ed. Chichester: John Wiley and Sons, Ltd, 2007: 217-26

11. Begaud B, Evreux JC, Jouglard J, et al. Imputation of the unexpected or toxic effects of drugs: actualization of the method used in France. Therapie 1985 Mar-Apr; 40 (2): 111-8

12. Edwards IR, Aronson JK. Adverse drug reactions: definitions, diagnosis, and management. Lancet 2000 Oct 7; 356 (9237): 1255-9

13. Nasrallah-Irles D, Castot A, Thomas L, et al. Signalement d'évènements indésirables par les patients: étude pilote réalisée avec la collaboration des associations de patients. Thérapie 2008; 63: 385-92

14. Herxheimer A, Crombag R, Alves TL. Direct patient reporting of adverse drug reactions: a fifteen-country survey \& literature review. Amsterdam: Health Action International (HAI) Europe, 2010 May

15. van Grootheest K, de Graaf L, de Jong-van den Berg LT. Consumer adverse drug reaction reporting: a new step in pharmacovigilance? Drug Saf 2003; 26 (4): 211-7

16. van Puijenbroek EP, Broos N, van Grootheest K. Monitoring adverse events of the vaccination campaign against influenza A (H1N1) in the Netherlands. Drug Saf 2010 Dec; 33 (12): 1097-108

17. Caillet C, Durrieu G, Jacquet A, et al. Safety surveillance of influenza $\mathrm{A}(\mathrm{H} 1 \mathrm{~N} 1) \mathrm{v}$ monovalent vaccines during the 20092010 mass vaccination campaign in France. Eur J Clin Pharmacol 2010 Jun; 67 (6): 649-51
18. Vellozzi C, Burwen DR, Dobardzic A, et al. Safety of trivalent inactivated influenza vaccines in adults: background for pandemic influenza vaccine safety monitoring. Vaccine 2009; (27): 2114-20

19. Bagheri H, Gony M, Montastruc JL. Meningococcal serogroup $\mathrm{C}$ vaccine: a pharmacovigilance point of view. Therapie 2005 May-Jun; 60 (3): 287-94

20. Blenkinsopp A, Wilkie P, Wang M, et al. Patient reporting of suspected adverse drug reactions: a review of published literature and international experience. Br J Clin Pharmacol 2007 Feb; 63 (2): 148-56

21. Mitchell AS, Henry DA, Sanson-Fisher R, et al. Patients as a direct source of information on adverse drug reactions. BMJ 1988 Oct 8; 297 (6653): 891-3

22. Egberts TC, Smulders M, de Koning FH, et al. Can adverse drug reactions be detected earlier? A comparison of reports by patients and professionals. BMJ 1996 Aug 31; 313 (7056): 530-1

23. Miller E. Vaccine Safety Surveillance. In: Talbot J, Waller P, editors. Stephens' detection of new adverse drug reactions. 5th ed: John Wiley and Sons, 2004: 571-90

24. Aagaard L, Nielsen LH, Hansen EH. Consumer reporting of adverse drug reactions: a retrospective analysis of the Danish adverse drug reaction database from 2004 to 2006 Drug Saf 2009; 32 (11): 1067-74

25. Egberts ACG, De Koning FHP, Meyboom RHB, et al. ADR related questions received by a telephone medicines information service and ADRs received by a spontaneous ADR reporting system: a comparison regarding patients and drugs. Pharmacoepidemiol Drug Saf 1997; 6 (4): 269-76

26. McLernon DJ, Bond CM, Hannaford PC, et al. Adverse drug reaction reporting in the $\mathrm{UK}$ : a retrospective observational comparison of yellow card reports submitted by patients and healthcare professionals. Drug Saf 2010 Sep 1; 33 (9): 775-88

27. van Hunsel F, Passier A, van Grootheest K. Comparing patients' and healthcare professionals' ADR reports after media attention: the broadcast of a Dutch television programme about the benefits and risks of statins as an example. Br J Clin Pharmacol 2009 May; 67 (5): 558-64

28. Medawar C, Herxheimer A. A comparison of adverse drug reaction reports from professionals and users, relating to risk of dependence and suicidal behaviour with paroxetine. Int J Risk Saf Med 2004; 16 (1): 5-19

29. van Grootheest K, van Puijenbroek EP, de Jong-van den Berg LT. Do pharmacists' reports of adverse drug reactions reflect patients' concerns? Pharm World Sci 2004 Jun; 26 (3): 155-9

30. de Langen J, van Hunsel F, Passier A, et al. Adverse drug reaction reporting by patients in the Netherlands: three years of experience. Drug Saf 2008; 31 (6): 515-24

31. Arrêté du 10 juin 2011 pris pour l'application des articles R. 5121-154, R 5121-167 et R. 5121-179 du code de la santé publique et relatif aux modalités de signalement des évènements indésirables par les patients et les associations agréées de patients

Correspondence: Dr Geneviève Durrieu, Laboratoire de Pharmacologie Médicale et Clinique, Faculté de Médecine, 37 allées Jules Guesde, 31000 Toulouse, France.

E-mail: genevieve.durrieu@univ-tlse3.fr 